\title{
Stable silver isotope fractionation in the natural transformation process of silver nanoparticles
}

\author{
Dawei Lu, Qian Liu^, Tuoya Zhang, Yong Cai, Yongguang Yin and Guibin Jiang
}

Nanoparticles in the environment can form by natural processes or be released due to human activities'. Owing to limited analytical methods, the behaviour of nanoparticles in the natural environment is poorly understood and until now they have only been described by the variations in the nanoparticle size or the concentration of the element of interest. Here we show that by using inductively coupled plasma mass spectrometry to measure silver $(\mathbf{A g})$ isotope ratios it is possible to understand the transformation processes of silver nanoparticles (AgNPs) in the environment. We found that the formation and dissolution of AgNPs under natural conditions caused significant variations in the ratio of natural $\mathrm{Ag}$ isotopes $\left({ }^{107} \mathrm{Ag}\right.$ and $\left.{ }^{109} \mathrm{Ag}\right)$ with an isotopic enrichment factor $(\varepsilon)$ up to $0.86 \%$. Furthermore, we show that engineered AgNPs have distinctly different isotope fractionation effects to their naturally formed counterparts. Further studies will be needed to understand whether isotope analysis can be used to reveal the sources of AgNPs in the environment.

AgNPs are the most widely used nanomaterial due to their broad spectrum in antimicrobial activities ${ }^{2}$. An exponential increase in the environmental levels of AgNPs is predicted due to their rising usage and disposal levels ${ }^{3,4}$. As the natural abundance of Ag in the Earth's crust is extremely low $\left(\sim 0.07 \mathrm{mg} \mathrm{kg}^{-1}\right.$; ref. 5), the release of even a small mass of $\mathrm{Ag}$ to the environment from anthropogenic activities may lead to proportionally large deviations from natural conditions ${ }^{6}$. AgNPs present in the environment are normally thought to originate from human activities. However, recent studies reveal that AgNPs can also form naturally via the reduction of $\mathrm{Ag}^{+}$in natural waters mediated by dissolved organic matter $(\mathrm{DOM})^{7,8}$ and sunlight ${ }^{9}$, which implies that the level of AgNPs in the environment may be underestimated. There is evidence that AgNPs are potentially harmful for organisms and human health ${ }^{1}$ and that AgNP loading can significantly influence important ecosystem processes $^{10,11}$. However, little is known about the natural processes and fate of AgNPs due to the lack of proper methods to detect or trace AgNPs in environmental media.

Here, we studied the variations in the stable Ag isotope ratio in the natural transformation process of AgNPs. Ag isotopes have previously been applied as chronometers for early-stage planetary differentiation ${ }^{12,13}$ and as tracers in archaeometry ${ }^{14,15}$, whereas other applications are rare in the literature. Naturally occurring $\mathrm{Ag}$ is composed of ${ }^{107} \mathrm{Ag}$ and ${ }^{109} \mathrm{Ag}$ with approximately equal natural abundances (51.8\% versus $48.2 \%$ ) and subtle variations in ${ }^{107} \mathrm{Ag} /{ }^{109} \mathrm{Ag}$ ratio were observed in various terrestrial samples ${ }^{16,17}$. We hypothesized that variations in the natural stable isotope ratio may provide a new means to study the environmental processes of NPs. To test this hypothesis, we studied two reversible processes of AgNPs in natural waters (Fig. 1): the formation of AgNPs via the reduction of $\mathrm{Ag}^{+}$in the presence of DOM and the dissolution of AgNPs to release $\mathrm{Ag}^{+}$. Other processes that are probably concurrent, such as adsorption of $\mathrm{Ag}^{+}$to AgNPs and the photoreduction of $\mathrm{Ag}$ salts (Fig. 1), were also considered. Ag isotope ratios were measured using multicollector inductively coupled plasma mass spectrometry (MC-ICP-MS) with a method uncertainty of $0.04 \%$ ( 2 s.d.). The Ag isotope ratio $\left({ }^{109} \mathrm{Ag} /{ }^{107} \mathrm{Ag}\right)$ in a sample is described by a $\delta$ value relative to an Ag isotope standard solution (NIST SRM 978a):

$$
\delta^{109} \mathrm{Ag}=\left(\frac{R_{\mathrm{T}}^{\text {sample }}}{R_{\mathrm{T}}^{\text {standard }}}-1\right) \times 1000 \%
$$

where $R_{\mathrm{T}}^{\text {sample }}$ and $R_{\mathrm{T}}^{\text {standard }}$ are mass bias corrected ratios in the sample and standard, respectively. $\Delta^{109} \mathrm{Ag}$ represents the difference in $\delta^{109} \mathrm{Ag}$ between the product and the remaining reactant unless otherwise noted:

$$
\Delta^{109} \mathrm{Ag}=\delta^{109} \mathrm{Ag} \text { product }-\delta^{109} \mathrm{Ag}_{\text {remaining.reactant }}
$$

We first studied the $\mathrm{Ag}$ isotope fractionation caused by the formation of AgNPs from the reduction of $\mathrm{Ag}^{+}$in the presence of DOM with Suwannee River humic acid (HA) as a model DOM and $\mathrm{AgClO}_{4}$ as a precursor. As shown in Fig. 2a and Supplementary Fig. 1, the exposure of the $\mathrm{Ag}^{+}$solution to sunlight in the presence of HA quickly produced AgNPs, as evidenced by a wide absorption peak at $\sim 440 \mathrm{~nm}$ corresponding to the feature surface plasmon resonance of AgNPs. The yield of AgNPs is strongly dependent on the HA concentration. Transmission electron microscopy (TEM) measurements indicated that the formed AgNPs were spherical particles with an average diameter of $\sim 45 \mathrm{~nm}$ (Fig. 2b). The possible chemical reactions that account for the formation of AgNPs in natural waters are as follows ${ }^{9,18}$ :

$$
\begin{gathered}
\mathrm{HA}_{\mathrm{red}}+\mathrm{O}_{2} \rightarrow \mathrm{HA}_{\mathrm{ox}}+\mathrm{O}_{2}^{\bullet-} \\
\mathrm{Ag}^{+}+\mathrm{O}_{2}^{\bullet-} \rightarrow \mathrm{Ag}^{0}(\mathrm{AgNP})+\mathrm{O}_{2}
\end{gathered}
$$

where $\mathrm{HA}_{\text {red }}$ and $\mathrm{HA}_{\mathrm{ox}}$ are the reduced and oxidized forms of $\mathrm{HA}$ as an example of DOM. Notably, we found that even at nanomolar concentrations of $\mathrm{Ag}^{+}$the formation of AgNPs in natural waters was also possible (Supplementary Fig. 2).

Figure $2 \mathrm{c}$ shows the $\mathrm{Ag}$ isotopic compositions of $\mathrm{AgClO}_{4}$ and the formed AgNPs at different HA concentrations. The relative fraction of $\mathrm{Ag}^{+}$that reacted was in the range of $5.9-20.6 \%$. The $\delta^{109} \mathrm{Ag}$ value of $\mathrm{AgClO}_{4}$ was $0.15 \pm 0.04 \%$ (mean \pm 2 s.d., $n=3$ ) and that of the AgNPs shifted positively, ranging from $(0.72 \pm 0.04 \%$ o $)$ to $(0.88 \pm 0.04 \%$ o $)$. This represented a significant fractionation $\left(P<10^{-5}\right)$ of $\mathrm{Ag}$ isotopes. The AgNPs were enriched in the heavy isotope and the residual $\mathrm{Ag}^{+}$was enriched in the light isotope. Assuming that the fractionation followed the Rayleigh model $^{19}, \varepsilon$ was estimated to be $0.63,0.73$ and $0.82 \%$ for HA concentrations of 5,10 and $50 \mathrm{mg} \mathrm{l}^{-1}$, respectively (Supplementary Fig. 3). 


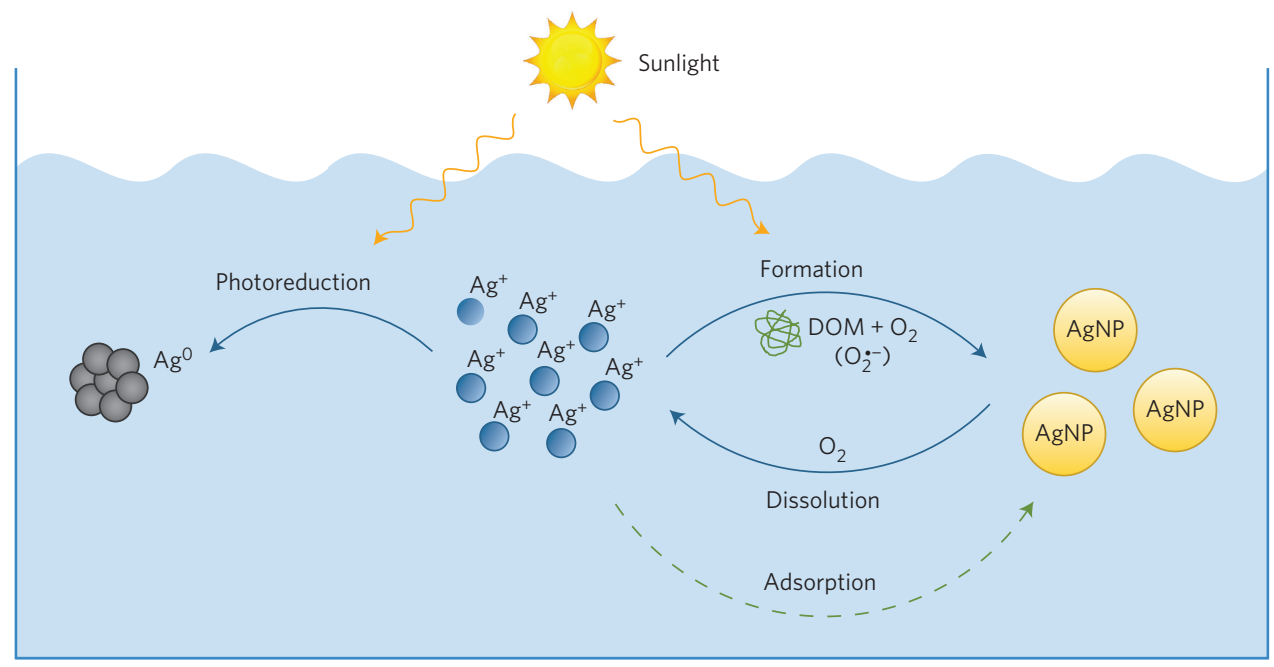

Figure 1 | Reactions and physical processes of AgNPs and $\mathrm{Ag}^{+}$in DOM-containing natural waters. $\mathrm{Ag}^{+}$can be reduced to form $\mathrm{AgNPs}$ in a process mediated by DOM and sunlight, and the dissolution of $\mathrm{AgNPs}$ can release $\mathrm{Ag}^{+}$. Meanwhile $\mathrm{Ag}^{+}$can also be transformed into $\mathrm{Ag}^{\circ}$ precipitates via photoreduction or adsorbed to the surface of AgNPs. Ag isotope fractionations caused by these processes were measured. The solid blue and dotted green arrows indicate chemical and physical processes, respectively.

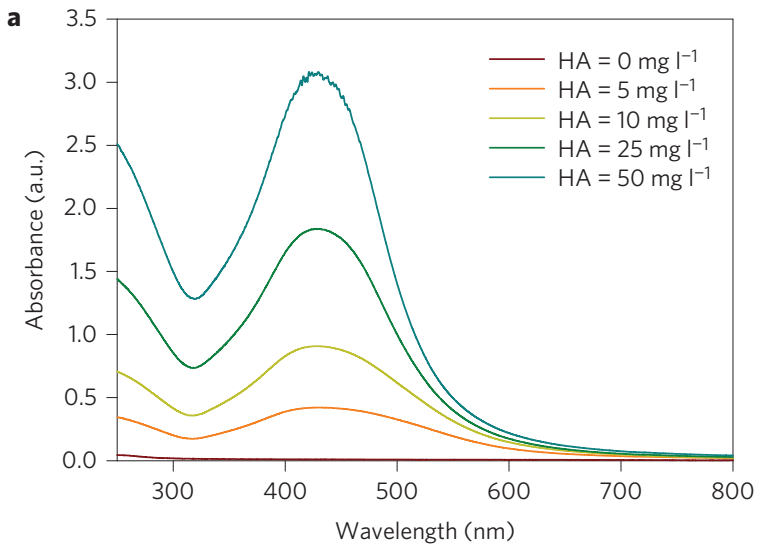

b

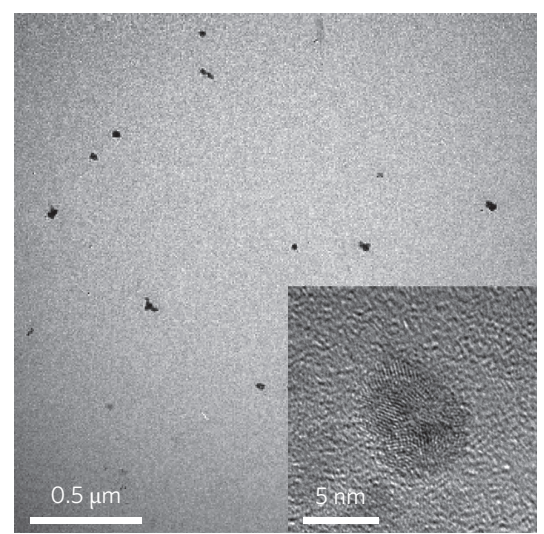

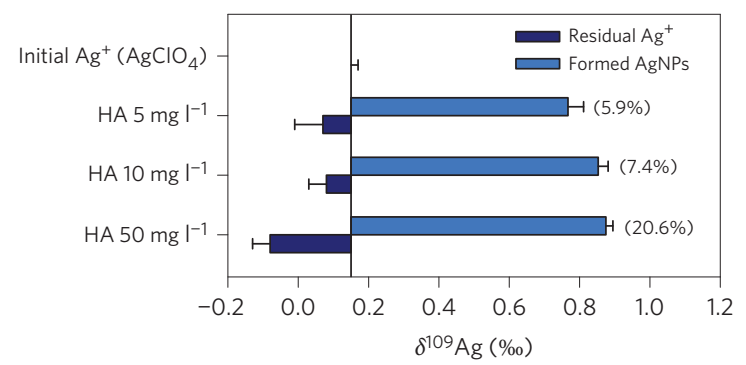

d
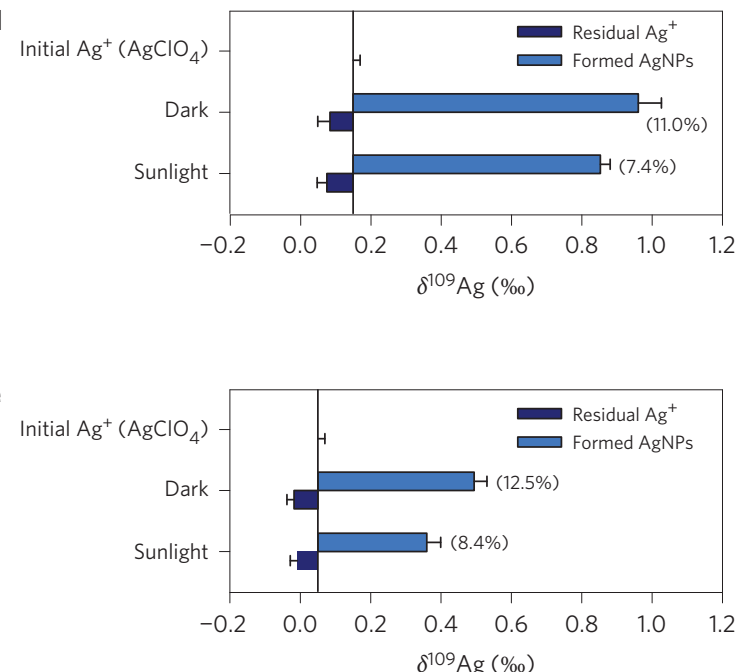

Figure 2 | Ag isotope fractionation in the HA-mediated formation of AgNPs. a, Absorption spectra of the $\mathrm{AgClO}_{4}$ solution after exposure to sunlight for $48 \mathrm{~h}$ at varying concentrations of HA (0-50 mg l-1 $)$. b. Typical TEM image of the formed AgNPs. Inset, a high-resolution TEM image of a single AgNP. c, $\mathrm{Ag}$ isotopic compositions of the formed $\mathrm{AgNPs}$ and the residual $\mathrm{Ag}^{+}$at different $\mathrm{HA}$ concentrations under sunlight. $\mathbf{d}$,e, The effects of sunlight on $\mathrm{Ag}$ isotope fractionation in the formation of $\mathrm{AgNPs}$ using $\mathrm{AgClO}_{4}(\mathbf{d})$ and $\mathrm{AgNO}_{3}(\mathbf{e})$ as precursors. In c-e the percentages in parentheses represent the relative fraction of $\mathrm{Ag}^{+}$reacted (that is, the percentages of reduced $\mathrm{Ag}^{+}$in the total $\mathrm{Ag}$ ). The bars start from the $\delta^{109} \mathrm{Ag}$ value of the initial $\mathrm{Ag}^{+}$concentration. The data in c-e are also given in Supplementary Tables 1 and 2 for a mass balance calculation. The error bars represent 1 s.d. from three parallel experiments $(n=3)$.

As sunlight is an important factor in the formation of AgNPs in natural waters ${ }^{9}$, the effects of sunlight were studied. We found that AgNPs could also form in the dark but the rate of formation was much slower (Supplementary Fig. 4). The formation of AgNPs in the dark also caused a significant $\mathrm{Ag}$ isotope fractionation $\left(P<10^{-5}\right.$; Fig. $\left.2 \mathrm{~d}\right)$ and the modelled $\varepsilon$ value in the dark was even 
a
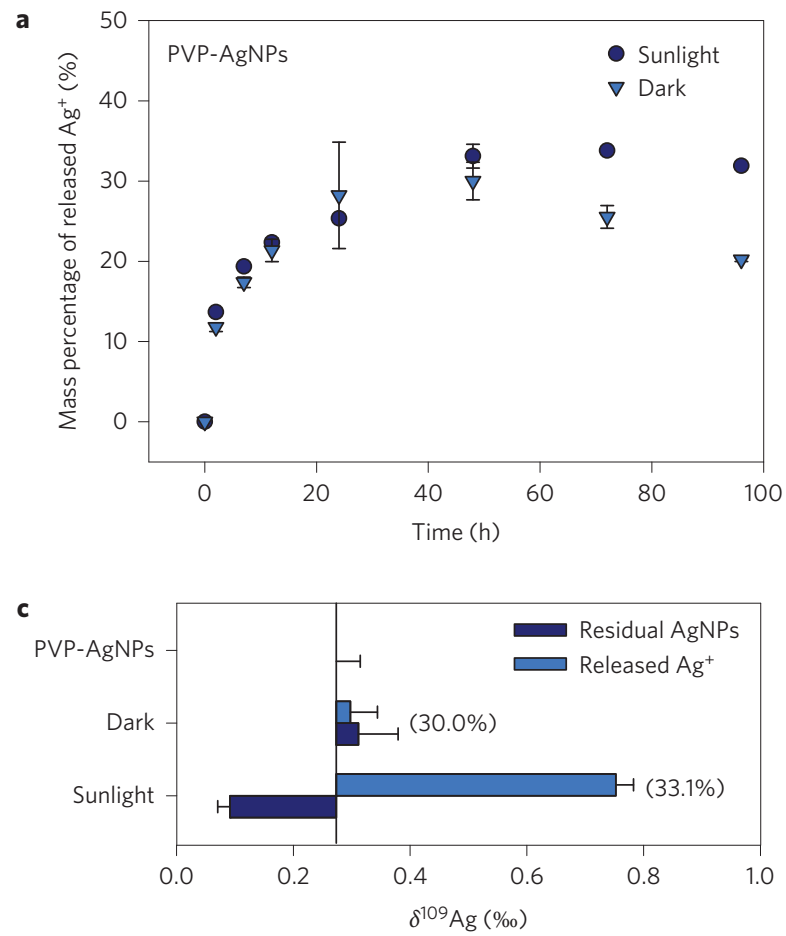

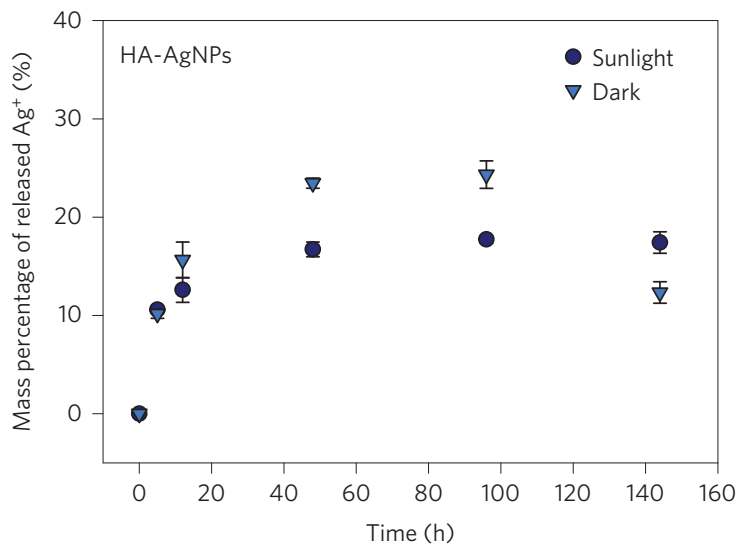

d

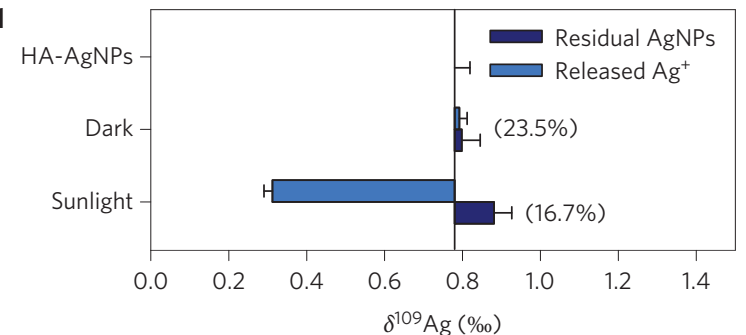

Figure 3 | Ag isotope fractionation in the dissolution of AgNPs. a,b, The kinetics of $\mathrm{Ag}^{+}$release from PVP-AgNPs (a) and HA-AgNPs (b) under dark and sunlight conditions. c,d, $\mathrm{Ag}$ isotope fractionation during the release of $\mathrm{Ag}^{+}$from PVP-AgNPs (c) and HA-AgNPs (d). The Ag isotope ratios in the lower panels were measured at the $48 \mathrm{~h}$ time point in the upper panels. In $\mathbf{c}, \mathbf{d}$, the percentages in parentheses represent the relative fraction reacted of AgNPs (that is, the percentages of AgNPs dissolved). The bars start from the $\delta^{109} \mathrm{Ag}$ of the initial AgNPs. The data in c,d are also given in Supplementary Table 3 for a mass balance calculation. The error bars represent 1 s.d. from three parallel experiments $(n=3)$.

larger than that under sunlight $(0.86 \%$ for the dark and $0.73 \%$ for sunlight; Supplementary Fig. 5). Given that counterions can affect the hydration structure and complex formation of $\mathrm{Ag}^{+}$in solution ${ }^{20}$, experiments were also performed using $\mathrm{AgNO}_{3}$ as a precursor and similar results were obtained (the modelled $\varepsilon$ value was $0.48 \%$ for the dark and $0.32 \%$ for sunlight; Fig. $2 \mathrm{e}$ and Supplementary Fig. 5). Significant Ag isotope fractionation was also observed when lowering the initial concentration of $\mathrm{Ag}^{+}$(Supplementary Fig. 6).

We then studied the dissolution of AgNPs in aqueous media. The experiment was carried out using both engineered polyvinylpyrrolidone-coated AgNPs (PVP-AgNPs; Supplementary Fig. 7) and HA-AgNPs (that is, AgNPs formed by the reduction of $\mathrm{Ag}^{+}$with HA) as models of naturally formed AgNPs. The dissolution of AgNPs is a reverse reaction of the natural formation, in which dissolved oxygen plays a key role ${ }^{21}$ :

$$
\mathrm{Ag}^{0}(\mathrm{AgNP})+\mathrm{O}_{2} \rightarrow \mathrm{Ag}^{+}+\mathrm{O}_{2}^{\bullet-}
$$

Figure 3a,b show the kinetics of $\mathrm{Ag}^{+}$release from PVP- and HAAgNPs under sunlight and dark conditions. The mass of $\mathrm{Ag}^{+}$ released from both PVP- and HA-AgNPs reached a maximum in $\sim 48 \mathrm{~h}$, with PVP-AgNPs releasing more $\mathrm{Ag}^{+}$than HA-AgNPs. The mass of released $\mathrm{Ag}^{+}$showed a declining trend beyond $48 \mathrm{~h}$. A purge of air into the solution did not change the declining trend (Supplementary Fig. 8), indicating that it was not resulting from the depletion of dissolved oxygen. This may be related to the readsorption of $\mathrm{Ag}^{+}$to AgNPs. For PVP-AgNPs more $\mathrm{Ag}^{+}$ was released under sunlight than in the dark, probably because ultraviolet-irradiation-induced oxidation could degrade PVP to carboxylic acid and $\mathrm{CO}_{2}^{22}$. In contrast, $\mathrm{HA}$-AgNPs released less $\mathrm{Ag}^{+}$under sunlight than in the dark.

The Ag isotope fractionation in the dissolution of PVP-AgNPs is shown in Fig. 3c. In the dark no significant isotope fractionation was observed $(P=0.237)$. Under sunlight, the relative fraction reacted of AgNPs was close to that in the dark, but the fractionation was greatly aggravated with the released $\mathrm{Ag}^{+}$being enriched in ${ }^{109} \mathrm{Ag}$ $\left(\Delta^{109} \mathrm{Ag}=0.66 \% ; P<10^{-3}\right)$. The initial concentration of AgNPs did not significantly affect the isotope fractionation (Supplementary Fig. 9). In the case of the HA-AgNPs (Fig. 3d), the fractionation was also minimal in the dark $\left(\triangle^{109} \mathrm{Ag}=-0.17 \% ; P=0.014\right)$ but significantly larger under sunlight $\left(\Delta^{109} \mathrm{Ag}=-0.57 \% ; P<10^{-4}\right)$. This trend would be observed at different relative fractions of reacted AgNPs assuming an equilibrium fractionation model (Supplementary Fig. 10). Notably, the released $\mathrm{Ag}^{+}$from HA-AgNPs was enriched in ${ }^{107} \mathrm{Ag}$, which was opposite to that from PVP-AgNPs. In addition to PVP-AgNPs, we also studied the dissolution of citrate-coated AgNPs (Cit-AgNPs), another important type of engineered AgNPs. We found that the $\mathrm{Ag}^{+}$released from Cit-AgNPs was enriched in ${ }^{109} \mathrm{Ag}$ (Supplementary Fig. 11), which was consistent with PVP-AgNPs.

To figure out the role of $\mathrm{Ag}^{+}$adsorption in the formation and dissolution of AgNPs we separately studied the Ag isotope fractionation caused by $\mathrm{Ag}^{+}$adsorption to PVP and HA. We found that most of $\mathrm{Ag}^{+}$in solution could be adsorbed to PVP or HA in $\sim 2 \mathrm{~h}$ (Supplementary Fig. 12). As shown in Fig. 4a, adsorption of $\mathrm{Ag}^{+}$ to PVP or HA could result in a slight Ag isotope fractionation with the adsorbed $\mathrm{Ag}^{+}$being enriched in ${ }^{109} \mathrm{Ag}\left(\Delta^{109} \mathrm{Ag}=0.26 \%\right.$ for HA and $0.20 \%$ for PVP; $P<0.01)$. Furthermore, the $\mathrm{Ag}$ isotope fractionation resulting from the photoreduction of $\mathrm{Ag}$ salts was also investigated to investigate the photosensitivity of Ag. Black $\mathrm{Ag}^{0}$ precipitation (non-nanosized without the feature surface plasmon resonance of AgNPs in absorption spectra) was observed when $\mathrm{AgClO}_{4}$ and $\mathrm{AgNO}_{3}$ solutions were exposed to sunlight. The photoreduction of $\mathrm{Ag}$ salts caused the remaining $\mathrm{Ag}^{+}$ to be enriched in ${ }^{107} \mathrm{Ag}$ and the precipitates to be enriched in ${ }^{109} \mathrm{Ag}$ $\left(\Delta^{109} \mathrm{Ag}=0.20 \%\right.$ for $\mathrm{AgClO}_{4}$ and $0.27 \%$ o for $\mathrm{AgNO}_{3}$; Fig. $4 \mathrm{~b}$ ). Possible mechanisms for the isotope fractionation caused by $\mathrm{Ag}^{+}$ 

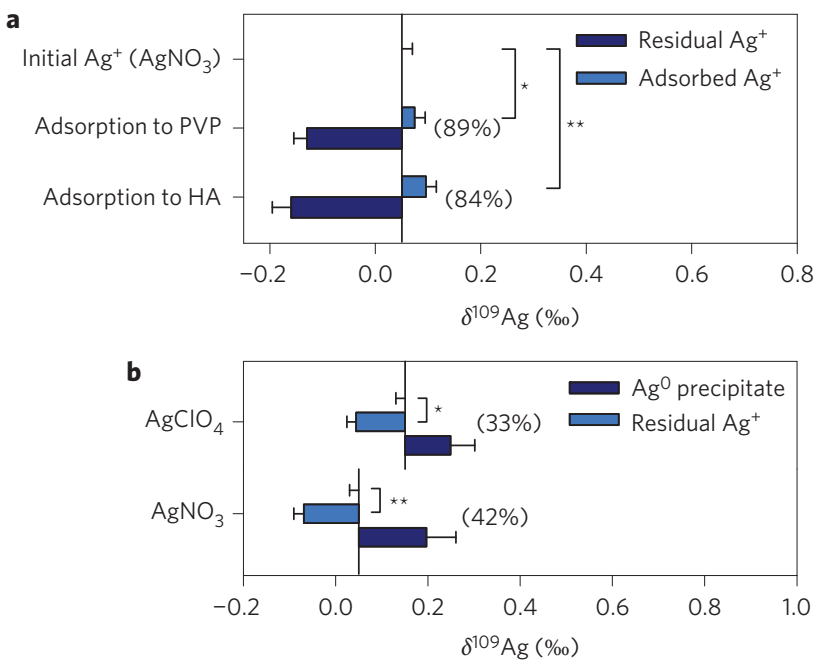

Figure 4 | $\mathrm{Ag}$ isotope fractionation in the adsorption of $\mathrm{Ag}^{+}$and the photoreduction of $\mathrm{Ag}$ salts. $\mathbf{a}, \mathrm{Ag}$ isotope fractionation in the adsorption of $\mathrm{Ag}^{+}$to $\mathrm{PVP}$ and $\mathrm{HA}$. ${ }^{\star} \mathrm{P}<10^{-2}$; ${ }^{\star \star} P<10^{-2}$. PVP and $\mathrm{HA}$ were coated on gold nanoparticles (AuNPs) to exclude the interference from AgNPs (see Supplementary Section 1.4 for details). The percentages in parentheses represent the relative fraction of $\mathrm{Ag}^{+}$reacted (that is, the percentages of adsorbed $\mathrm{Ag}^{+}$in the total $\mathrm{Ag}^{+}$). It should be noted that the $\delta^{109} \mathrm{Ag}$ values of adsorbed $\mathrm{Ag}^{+}$were calculated by mass balance and other data were measured. $\mathbf{b}, \mathrm{Ag}$ isotope fractionation in the photoreduction of $\mathrm{Ag}$ salts. ${ }^{\star} P<10^{-2}$; ${ }^{\star} P<10^{-2}$. Aqueous solutions of $\mathrm{AgClO}_{4}$ and $\mathrm{AgNO}_{3}\left(200 \mathrm{mg} \mathrm{l}^{-1}\right)$ were exposed to sunlight for two weeks and then the isotope ratios of the residual $\mathrm{Ag}^{+}$and $\mathrm{Ag}^{0}$ precipitates were measured. The percentages in parentheses represent the relative fraction of $\mathrm{Ag}^{+}$reacted (that is, the percentages of photoreduced $\mathrm{Ag}^{+}$). The bars start from the $\delta^{109} \mathrm{Ag}$ of the initial reactants. The data are also given in Supplementary Tables 4 and 5 for a mass balance calculation. The error bars represent $1 \mathrm{~s}$.d. from three parallel experiments $(n=3)$.

adsorption and the photoreduction of $\mathrm{Ag}$ salts are discussed in Supplementary Section 2.1.

From the aforementioned results it is clear that the natural formation and dissolution of AgNPs are accompanied by significant Ag isotope fractionation. The observed fractionations could be comparable to the largest variations in the ${ }^{109} \mathrm{Ag} /{ }^{107} \mathrm{Ag}$ ratio found in terrestrial samples-such as native Ag metal from globally distributed mines $(\sim 0.6 \%)^{12}$, Ag-fortified consumer products and environmental samples (up to $0.83 \%$ ) ) $^{16,23}$-and are much larger than those observed in the process of $\mathrm{Ag}^{+}$precipitation with $\mathrm{Cl}^{-}(0.17 \% \text { o })^{24}$. $\mathrm{Ag}$ is highly reactive and may be involved in natural processes such as oxidation, sulfidation and precipitation. Taking into account the significant $\mathrm{Ag}$ isotope fractionation observed here and the increasing levels of AgNPs discharged into the environment ${ }^{3,4}$, it is possible to infer that natural transformation processes of AgNPs may play an important role in natural $\mathrm{Ag}$ isotope fractionation.

Stable isotopic signatures could indicate the presence of concurrent processes. In Fig. $2 \mathrm{~d}$, the AgNPs formed in the dark were isotopically heavier than those formed under sunlight by $0.11 \%$ $(P=0.039)$, which could be attributed to the fractionation caused by the photoreduction of $\mathrm{Ag}$ salts (that is, the depletion of the heavy isotope in the solution; Fig. 4b). This could suggest that the formation of AgNPs under sunlight was accompanied by the photoreduction of Ag salts and that the apparent isotope fractionation was the joint outcome of these two processes (Fig. 1).

Stable isotope fractionation could provide insight into the mechanism of AgNP formation. In the natural formation of AgNPs the same fractionation direction (that is, the enrichment of the heavy isotope in the product) of the formation of HA-AgNPs as the adosrption of $\mathrm{Ag}^{+}$to $\mathrm{HA}$ could potentially explain why the HA-AgNPs were enriched in ${ }^{109} \mathrm{Ag}$ and reveal the role of $\mathrm{Ag}^{+}$ adsorption in the formation of HA-AgNPs (see Supplementary Section 2.2 for detailed discussion).

Stable isotope fractionation could also reveal the dissolution pathways of AgNPs. The dissolution of PVP-AgNPs under sunlight showed a significant enrichment of ${ }^{109} \mathrm{Ag}$ in the released $\mathrm{Ag}^{+}$ $\left(P<10^{-3}\right.$; Fig. 3c). This could be explained by a photo-oxidationinduced formation of an intermediate metal oxide phase $\left(\mathrm{Ag}_{2} \mathrm{O}\right.$, for example) at the surface of the $\mathrm{AgNPs}^{25,26}$. According to equilibrium isotope fractionation rules ${ }^{19}$, the heavy isotope is prone to being concentrated in compounds with a higher oxidation state. As a result, the metal oxide phase should be enriched in ${ }^{109} \mathrm{Ag}$, thus causing the released $\mathrm{Ag}^{+}$to be enriched in ${ }^{109} \mathrm{Ag}$. However, the fractionation was not significant in the dark $(P=0.237$; Fig. 3c). Such a difference between sunlight and dark conditions might suggest a different dissolution mechanism in the dark, such as a direct oxidation pathway in the absence of the formation of a metal oxide phase ${ }^{21}$. Comparing the isotope fractionation effects in the dissolution of different AgNPs (Fig. 3c-d and Supplementary Fig. 11), the $\mathrm{Ag}^{+}$released from PVP- and Cit-AgNPs was enriched in ${ }^{109} \mathrm{Ag}$, whereas that from HA-AgNPs was enriched in ${ }^{107} \mathrm{Ag}$. This observation implied that there should be an extra process that depleted ${ }^{109} \mathrm{Ag}$ in the released $\mathrm{Ag}^{+}$during the dissolution of HAAgNPs. We noted that this effect matched the fractionation caused by the HA-mediated reduction of $\mathrm{Ag}^{+}$, in which ${ }^{109} \mathrm{Ag}^{+}$ was preferentially reduced by $\mathrm{HA}$ (Fig. 2c-e). Therefore, we propose the dissolution pathways of AgNPs as in Fig. 5. For engineered AgNPs (Fig. 5a), their coatings (such as PVP and citrate), despite having some redox activities, are unable to reduce $\mathrm{Ag}^{+}$

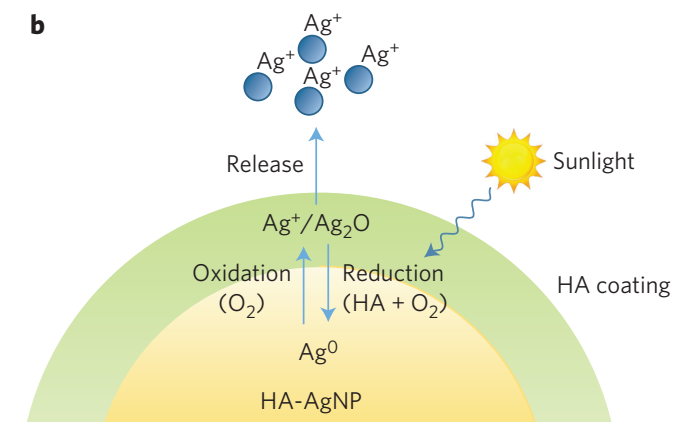

Figure 5 | Proposed dissolution pathways of AgNPs. a, For PVP-AgNPs, the $\mathrm{Ag}^{0}$ is oxidized to $\mathrm{Ag}^{+} / \mathrm{Ag}_{2} \mathrm{O}$, releasing $\mathrm{Ag}^{+}$. b, For $\mathrm{HA}-\mathrm{AgNPs}, \mathrm{HA}$ has a stronger reducing ability than PVP under natural conditions, and thereby the released $\mathrm{Ag}^{+}$can be reduced back to $\mathrm{Ag}^{\circ}$ by the $\mathrm{HA}$ coating under sunlight. The different dissolution pathways of PVP-AgNPs (a) and HA-AgNPs (b) cause the released $\mathrm{Ag}^{+}$to be enriched in different isotopes. The blue and green zones represent PVP and HA coatings, respectively. 
under such mild natural conditions. Whereas for naturally formed HA-AgNPs (Fig. 5b), the HA coating can reduce $\mathrm{Ag}^{+}$back to $\mathrm{Ag}^{0}$ under natural conditions, in which ${ }^{109} \mathrm{Ag}^{+}$is preferentially reduced over ${ }^{107} \mathrm{Ag}^{+}$by the $\mathrm{HA}$ coating, thus leaving the final released $\mathrm{Ag}^{+}$to be enriched in ${ }^{107} \mathrm{Ag}$. These proposed pathways could also explain the results in Fig. 3a-b (see Supplementary Section 2.3).

From the discussion above, we learn that stable isotopes provide a unique tool for studying the processes of NPs. We inferred the underlying pathways from the apparent isotope fractionation effects. In contrast to methods that use isotopically enriched materials as tracers ${ }^{27,28}$, this method employs natural variations of the stable isotope ratios and does not require any artificial tracers. However, it should be noted that extensive sample purification would be necessary before analysis of the $\mathrm{Ag}$ isotope ratios of samples from the natural environment ${ }^{16}$.

Another important application of stable isotopes is source tracing. In this study, the observed $\delta^{109} \mathrm{Ag}$ values of naturally formed and engineered AgNPs were in the ranges of $0.29-0.97 \%$ o and $0.25-0.65 \%$, respectively, suggesting that $\delta^{109} \mathrm{Ag}$ values could not directly indicate the exact sources of AgNPs. However, naturally formed AgNPs showed an inverse isotope fractionation direction compared with engineered AgNPs in dissolution (that is, the released $\mathrm{Ag}^{+}$was enriched in different isotopes; Fig. 3). This result reveals the possibility of determining whether the AgNPs are naturally formed or engineered from their different isotope fractionation effects. Further studies are required to investigate whether or not high-precision Ag isotope analysis may be used as a technique to reveal the sources of AgNPs.

\section{Methods}

Methods and any associated references are available in the online version of the paper.

\section{Received 18 April 2015; accepted 10 May 2016;} published online 20 June 2016

\section{References}

1. Fabrega, J., Luoma, S. N., Tyler, C. R., Galloway, T. S. \& Lead, J. R. Silver nanoparticles: behaviour and effects in the aquatic environment. Environ. Int. 37, 517-531 (2011).

2. Nowack, B., Krug, H. F. \& Height, M. 120 years of nanosilver history: implications for policy makers. Environ. Sci. Technol. 45, 1177-1183 (2011).

3. Mueller, N. C. \& Nowack, B. Exposure modeling of engineered nanoparticles in the environment. Environ. Sci. Technol. 42, 4447-4453 (2008).

4. Gottschalk, F., Sonderer, T., Scholz, R. W. \& Nowack, B. Modeled environmental concentrations of engineered nanomaterials $\left(\mathrm{TiO}_{2}, \mathrm{ZnO}, \mathrm{Ag}, \mathrm{CNT}\right.$, fullerenes) for different regions. Environ. Sci. Technol. 43, 9216-9222 (2009).

5. Purcell, T. W. \& Peters, J. J. Sources of silver in the environment. Environ. Toxicol. Chem. 17, 539-546 (1998).

6. Luoma, S. N. Silver Nanotechnologies and the Environment: Old Problems or New Challenges? (Woodrow Wilson International Center for Scholars, 2008).

7. Akaighe, N. et al. Humic acid-induced silver nanoparticle formation under environmentally relevant conditions. Environ. Sci. Technol. 45, 3895-3901 (2011).

8. Adegboyega, N. F. et al. Interactions of aqueous $\mathrm{Ag}^{+}$with fulvic acids: mechanisms of silver nanoparticle formation and investigation of stability. Environ. Sci. Technol. 47, 757-764 (2013).

9. Yin, Y. G., Liu, J. F. \& Jiang, G. B. Sunlight-induced reduction of ionic $\mathrm{Ag}$ and $\mathrm{Au}$ to metallic nanoparticles by dissolved organic matter. ACS Nano 6, 7910-7919 (2012)

10. Pradhan, A., Seena, S., Pascoal, C. \& Cassio, F. Can metal nanoparticles be a threat to microbial decomposers of plant litter in streams? Microb. Ecol. 62, 58-68 (2011)

11. Choi, O. K. \& Hu, Z. Q. Nitrification inhibition by silver nanoparticles. Water Sci. Technol. 59, 1699-1702 (2009).
12. Hauri, E. H., Carlson, R. W. \& Bauer, J. The timing of core formation and volatile depletion in solar system objects from high-precision ${ }^{107} \mathrm{Pd}-{ }^{107} \mathrm{Ag}$ isotope systematics. Lunar Planet. Sci. Abs. 31, 1812 (2000).

13. Schonbachler, M., Carlson, R. W., Horan, M. F., Mock, T. D. \& Hauri, E. H. Silver isotope variations in chondrites: volatile depletion and the initial

${ }^{107} \mathrm{Pd}$ abundance of the solar system. Geochim. Cosmochim. Acta 72, 5330-5341 (2008).

14. Desaulty, A. M. \& Albarede, F. Copper, lead, and silver isotopes solve a major economic conundrum of Tudor and early Stuart Europe. Geology 41, 135-138 (2013).

15. Desaulty, A. M., Telouk, P., Albalat, E. \& Albarede, F. Isotopic Ag-Cu-Pb record of silver circulation through 16th-18th century Spain. Proc. Natl Acad. Sci. USA 108, 9002-9007 (2011).

16. Luo, Y., Dabek-Zlotorzynska, E., Celo, V., Muir, D. C. G. \& Yang, L. Accurate and precise determination of silver isotope fractionation in environmental samples by multicollector-ICPMS. Anal. Chem. 82, 3922-3928 (2010).

17. Chugaev, A. V. \& Chernyshev, I. V. High-precision measurement of ${ }^{107} \mathrm{Ag} /{ }^{109} \mathrm{Ag}$ in native silver and gold by multicollector inductively coupled plasma mass spectrometry (MC-ICP-MS). Geochem. Int. 50, 899-910 (2012).

18. Jones, A. M., Garg, S., He, D., Pham, A. N. \& Waite, T. D. Superoxide-mediated formation and charging of silver nanoparticles. Environ. Sci. Technol. 45 , 1428-1434 (2011)

19. Wiederhold, J. G. Metal stable isotope signatures as tracers in environmental geochemistry. Environ. Sci. Technol. 49, 2606-2624 (2015).

20. Yamaguchi, T., Lindqvist, O., Boyce, J. B. \& Claeson, T. Determination of the hydration structure of silver ions in aqueous silver perchlorate and nitrate solutions from EXAFS using synchrotron radiation. Acta Chem. Scand. A 38, 423-428 (1984).

21. Liu, J. Y. \& Hurt, R. H. Ion release kinetics and particle persistence in aqueous nano-silver colloids. Environ. Sci. Technol. 44, 2169-2175 (2010).

22. Horikoshi, S., Hidaka, H. \& Serpone, N. Photocatalyzed degradation of polymers in aqueous semiconductor suspensions: V. Photomineralization of lactam ring-pendant polyvinylpyrrolidone at titania/water interfaces. J. Photochem. Photobiol. A Chem. 138, 69-77 (2001).

23. Yang, L., Dabek-Zlotorzynska, E. \& Celo, V. High precision determination of silver isotope ratios in commercial products by MC-ICP-MS. J. Anal. Atom. Spectrom. 24, 1564-1569 (2009).

24. Luo, Y., Celo, V., Dabek-Zlotorzynska, E. \& Yang, L. Effects of precipitation and UV photolysis on Ag isotope ratio: experimental studies. J. Anal. Atom. Spectrom. 27, 299-304 (2012).

25. Gorham, J. M., Maccuspie, R. I., Klein, K. L., Fairbrother, D. H. \& Holbrook, R. D. UV-induced photochemical transformations of citrate-capped silver nanoparticle suspensions. J. Nanopart. Res. 14, 1139 (2012).

26. Grillet, N. et al. Photo-oxidation of individual silver nanoparticles: a real-time tracking of optical and morphological changes. J. Phys. Chem. C 117, 2274-2282 (2013).

27. Croteau, M. N., Dybowska, A. D., Luoma, S. N., Misra, S. K. \& Valsami-Jones, E. Isotopically modified silver nanoparticles to assess nanosilver bioavailability and toxicity at environmentally relevant exposures. Environ. Chem. 11, 247-256 (2014).

28. Laycock, A. et al. Synthesis and characterization of isotopically labeled silver nanoparticles for tracing studies. Environ. Sci. Nano 1, 271-283 (2014).

\section{Acknowledgements}

The authors acknowledge financial support from the Chinese Academy of Sciences (No. XDB14010400), the National Basic Research Program of China (2015CB931903, 2015CB932003) and the National Natural Science Foundation of China (No. 21377141, $21422509,91543104)$. Q.L. acknowledges the support from the Youth Innovation Promotion Association of CAS.

\section{Author contributions}

Q.L. and G.J. conceived and designed the experiments; D.L. and T.Z. performed the experiments; Q.L. and D.L. analyzed the data; Y.C. and Y.Y. gave comments on the paper; Q.L. and G.J. wrote the paper.

\section{Additional information}

Supplementary information is available in the online version of the paper. Reprints and permissions information is available online at www.nature.com/reprints. Correspondence and requests for materials should be addressed to Q.L. and G.J.

\section{Competing financial interests}

The authors declare no competing financial interests. 


\section{Methods}

Formation of AgNPs by the reduction of $\mathrm{Ag}^{+}$with DOM. An aqueous borate buffer solution $(0.2 \mathrm{M}, \mathrm{pH} 8.2,200 \mathrm{ml})$ containing $200 \mathrm{mg} \mathrm{l}^{-1} \mathrm{AgClO}_{4}$ and $10 \mathrm{mg} \mathrm{l}^{-1}$ HA was prepared. For experiments in sunlight, the mixture was exposed to simulated sunlight in an Intelligent Illumination incubator (SAIFE Co., China) for $48 \mathrm{~h}$. The irradiation intensity was $3000 \mathrm{LX}$, and the temperature was kept at $25 \pm 1{ }^{\circ} \mathrm{C}$. For experiments in the dark, the mixture was wrapped by aluminum foil and stored in dark for 7 days. The experiments were also carried out using $\mathrm{AgNO}_{3}$ as a precursor. Three parallel experiments were performed $(n=3)$. All experiments in sunlight were carried out under both real and simulated sunlight and the same directions of Ag isotope fractionation were observed. As it was difficult to control the intensity of real sunlight, data were collected only under simulated sunlight.

Dissolution of AgNPs. The AgNPs used for dissolution experiments were first thoroughly rinsed with water using a centrifugal ultrafilter device (Amicon Ultra-15, Millipore, MA) until the concentration of $\mathrm{Ag}^{+}$in the rinse solution did not change. Then, $9 \mathrm{ml}$ of AgNP dispersion ( $500 \mathrm{mg} \mathrm{l}^{-1}$ ) was sealed in a dialysis tube with a molecular weight cut-off (MWCO) of $7 \mathrm{kD}$ and immersed in $900 \mathrm{ml}$ of water with magnetic stirring to allow $\mathrm{Ag}^{+}$release for up to $144 \mathrm{~h}$. The $\mathrm{Ag}^{+}$ions could pass freely through the dialysis tube but AgNPs could not. The dialysis process has been examined to ensure that no artificial Ag isotope fractionation was caused (Supplementary Table 6). The experiments were performed under both sunlight and dark conditions and three parallel experiments were performed $(n=3)$. The effect of purge with air or nitrogen on the dissolution of AgNPs was also studied.

Measurement of $\mathbf{A g}$ isotope ratios by MC-ICP-MS. The Ag isotope ratio was measured using a Nu II Plasma MC-ICP-MS (Wrexham, UK) equipped with 16 Faraday cups and coupled to a DeSolvation Nebulizer System (DSN-100) working in a low-resolution mode. The optimized instrumental parameters are listed in Supplementary Table 7. All samples were diluted to an Ag concentration of $100 \mu \mathrm{g} \mathrm{l}^{-1}$. Samples were introduced into the plasma by using a self-aspiration nebulizer at a flow rate of $0.11 \mathrm{~min}^{-1}$. The procedure blank signals of $\mathrm{Ag}$ and $\mathrm{Pd}$ obtained in $3 \%(\mathrm{v} / \mathrm{v}) \mathrm{HNO}_{3}$ were subtracted from all sample and standard signals. Three parallel measurements were made for all samples $(n=3)$.

The mass bias was corrected based on a standard-sample-standard bracketing approach combined with the use of $\mathrm{Pd}$ as an internal standard, without assuming identical mass bias for $\mathrm{Pd}$ and $\mathrm{Ag}$, as described previously ${ }^{16,23}$. The ${ }^{108} \mathrm{Pd} /{ }^{106} \mathrm{Pd}$ ratio was used to correct the mass bias of ${ }^{109} \mathrm{Ag} /{ }^{107} \mathrm{Ag}$ ratio. As the true value of the ${ }^{108} \mathrm{Pd} /{ }^{106} \mathrm{Pd}$ ratio was unknown, the mass bias of ${ }^{108} \mathrm{Pd} /{ }^{106} \mathrm{Pd}$ ratio in two adjacent SRM 978a standard solutions was first corrected by the certified value of 1.07638 for ${ }^{107} \mathrm{Ag} /{ }^{109} \mathrm{Ag}$ in SRM 978a and their average value was then used for the correction of the ${ }^{109} \mathrm{Ag} /{ }^{107} \mathrm{Ag}$ ratio in the sample. The correction calculation was made by the Nu-Nice software (Wrexham, UK) based on the Russell exponential fractionation law:

$$
R_{\mathrm{M}}=R_{\mathrm{T}} \times\left(\frac{m_{\mathrm{i}}}{m_{\mathrm{j}}}\right)^{f}
$$

where $R_{\mathrm{M}}$ and $R_{\mathrm{T}}$ are the measured and corrected ratios, respectively, $m_{i}$ and $m_{j}$ are the absolute masses of the isotopes of interest and $f$ is the mass bias correction factor.

The Faraday cup configuration is given in Supplementary Table 8. Notably, ${ }^{111} \mathrm{Cd}$ was measured to mathematically remove possible interferences from ${ }^{106} \mathrm{Cd}$ and ${ }^{108} \mathrm{Cd}$ to ${ }^{106} \mathrm{Pd}$ and ${ }^{108} \mathrm{Pd}$ by using an iterative method (see Supplementary Section 1.7 for details). On the basis of this approach, a $\delta^{109} \mathrm{Ag}$ value of $0.00 \pm 0.04 \%$ o (mean \pm 2 s.d., $n=17$ ) in a $100 \mathrm{ng} \mathrm{g}^{-1}$ SRM 978a solution containing $100 \mathrm{ng} \mathrm{g}^{-1} \mathrm{Pd}$ was obtained. When the sample digestion process was included (Supplementary Table 6), the $\delta^{109} \mathrm{Ag}$ value was still $0.00 \pm 0.04 \%$ (mean \pm 2 s.d., $n=5$ ). The matrix effect in MC-ICP-MS measurement has also been evaluated (Supplementary

Table 6). These results prove that this approach is highly accurate and precise for the measurement of $\mathrm{Ag}$ isotope ratios. It should be noted that if the method is applied to environmental samples, extra purification steps (for example, ion exchange columns $^{16}$ ) are recommended before MC-ICP-MS analysis due to the more complex sample matrix. 